\title{
An Introduction to Image-Based Systems Biology of Multicellular Spheroids for Experimentalists and Theoreticians
}

\author{
Sabine C. Fischer \\ Center for Computational and Theoretical Biology, Department of Biology, Universität \\ Würzburg, Würzburg, Germany
}

Author for correspondence: Sabine C. Fischer, Center for Computational and Theoretical Biology, Department of Biology, Universität Würzburg, Emil-Fischer-Str. 32, 97074

Würzburg, Germany. Email: sabine.fischer@uni-wuerzburg.de

Doi: http://dx.doi.org/10.15586/computationalbiology.2019.ch1

\begin{abstract}
Multicellular organisms are inherently three-dimensional. This leads to complex intercellular interactions that cannot be reproduced in two-dimensional cell culture. Instead, three-dimensional spheroids, ball-shaped cell aggregates, arise as model systems. Spheroids provide an accurate in vitro representation of the three-dimensional organization of cells in tissues, and compared to a real tissue, they excel with well-defined experimental conditions, easy handling, and suitability for high-quality imaging. Therefore, spheroids are an experimental system that can be readily combined with mathematical modeling. This chapter shows how image-based systems biology is implemented for multicellular spheroids to study three-dimensional cell-cell interactions. The chapter is intended for experimentalists and theoreticians who plan to extend their research by linkage with other disciplines. The relevant concepts for experimental approaches and quantitative imaging are introduced and linked to mathematical models of spheroids. This results in a list of potential systems biology workflows for typical spheroid research areas in cell biology, cancer biology, and bioprinting. In all three areas, there is a large gap between the details of the mathematical models and the
\end{abstract}

In: Computational Biology. Holger Husi (Editor), Codon Publications, Brisbane, Australia. ISBN: 978-0-9944381-9-5; Doi: http://dx.doi.org/10.15586/computationalbiology.2019

Copyright: The Authors.

License: This open access article is licensed under Creative Commons Attribution 4.0 International (CC BY 4.0). https://creativecommons.org/licenses/by-nc/4.0/ 
available imaging data. The aim of this chapter is to encourage more interactions of experimentalists and theoreticians to fill this gap in spheroid research.

Keywords: agent-based model; continuous model; microscopy; spheroid formation; spheroid fusion

\section{INTRODUCTION}

Biomedical research in areas like cancer, infection, and developmental biology relies more and more on three-dimensional in vitro models including organoids, tissue explants, embryoid bodies, and spheroids (1). A major question in these research areas is how cellular interactions affect the overall behavior of the system. In this regard, multicellular spheroids are the best-studied system. They are three-dimensional, ball-shaped solid cellular aggregates that can be formed from various cell types (2). Originally, they have been formed by cancer cells and implemented as a model system for avascular tumors. Spheroids excel by well-defined experimental conditions, easy handling, as well as the suitability for high-quality imaging and generation of large sample sizes. Hence, they are an ideal model system to address the three-dimensional cellular arrangement, the behavior of individual cells within a tissue-like construct and the contribution of individual cells to the growth of the whole aggregate. Image-based systems biology provides an appropriate conceptual framework to tackle these questions (3). It combines experimental approaches with quantitative imaging data and spatial mathematical modeling (Figure 1). The collaboration of experimentalists and theoreticians

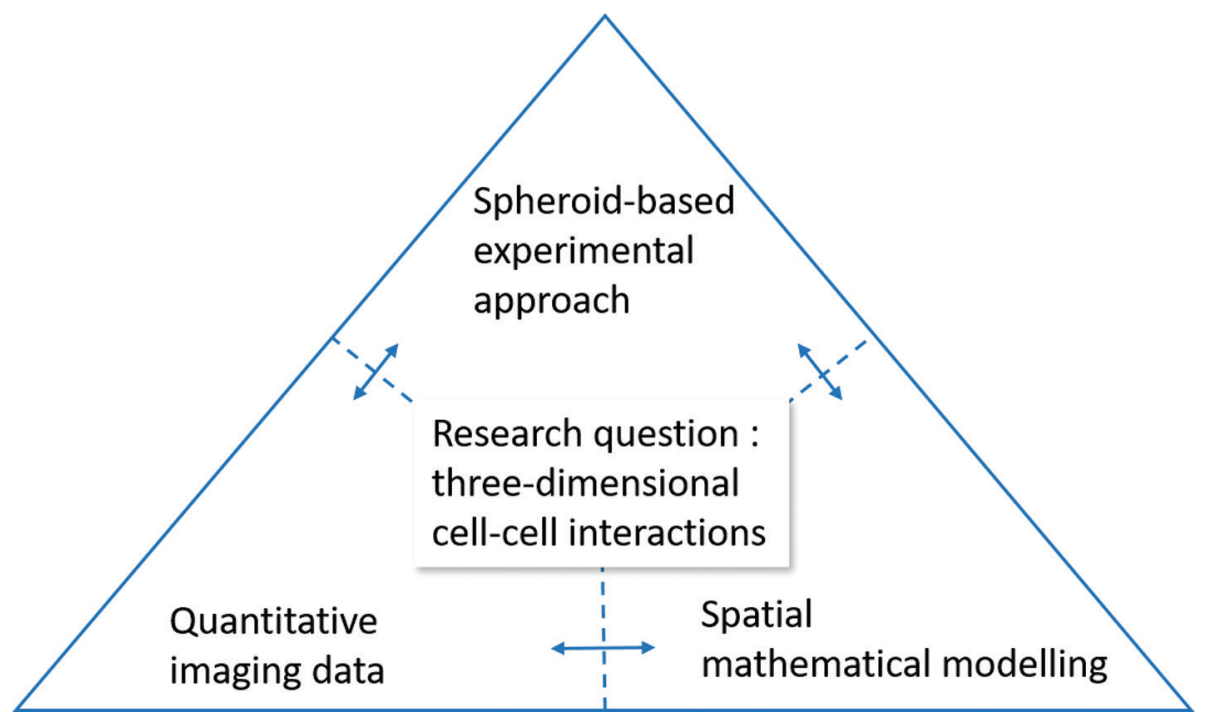

Figure 1 Image-based systems biology in spheroid research. The question of the mechanisms driving three-dimensional cell-cell interactions is tackled by a combination of experiments, quantitative imaging, and mathematical modeling. The three approaches have to be tightly linked. 
ideally starts with formulating a common research question. Subsequently, in preliminary studies, the experimental, imaging, and mathematical methods are developed, implemented, and matched. In the main study, all parts interact closely to test the existing hypotheses and generate new ones. This approach requires experts from three different fields and is therefore difficult to implement. In the field of spheroid research, only a few studies have conducted the whole cycle. By introducing the concepts for experimental setups, image, and data analysis as well as mathematical modeling of spheroids and suggesting workflows of how to combine them, this chapter aims at fostering more systems biology approaches in spheroid research.

\section{METHODS}

For an image-based systems biology approach, methods from four different categories have to be chosen: experimental approach, imaging, image analysis, and mathematical modeling. The methods have to be inter-linkable and most importantly appropriate for the research question. For example, the quantitative evaluation of the images should provide results that are readily comparable to the statistical readout from the mathematical model. Furthermore, these numbers should provide new insight regarding the question of interest.

\section{Experimental approaches}

There are three typical approaches for experimental setups involving spheroids (Table 1). The analysis of spheroid formation mainly focuses on how cells aggregate in three spatial dimensions. This provides insights into cellular aggregation, rearrangement, and adhesion. Fully formed spheroids are typically used to evaluate spheroid growth as well as the viability of the individual cells. Further questions investigated with spheroids could include detailed analyses of the behavior of individual cells like differentiation or potential rearrangement in the spheroid. The fusion of two or more spheroids helps to address questions regarding rearrangement of individual cells or whole cell aggregates as well as cell sorting.

\section{Imaging techniques}

Investigating cellular properties within the three-dimensional spheroid context requires the spatial information of each cell and the geometry of the entire spheroid. Classical methods for imaging spheroids have relied on

\section{TABLE $1 \quad$ Experimental approaches}

Research question

Aggregation, rearrangement, adhesion

Spheroid growth, viability, rearrangement, adhesion, differentiation

Rearrangement, sorting

\section{Experimental approach}

Spheroid formation

Fully formed spheroid

Spheroid fusion 
physical sectioning (4). More recent approaches rely on light microscopy of the intact spheroids. Each approach has its strengths and weaknesses. Hence, choosing the best approach for spheroid imaging depends heavily on the scientific question. Conventional light microscopy such as wide-field microscopy provides a global but two-dimensional picture of spheroids. Due to the high imaging speed and the possibility of imaging multi-well plates, it has widely been used for highcontent assays to characterize spheroid viability (5).

Confocal fluorescence microscopy enables imaging of spheroids at the single-cell level in three spatial dimensions. Standard confocal microscopes allow high-throughput imaging of multi-well plates, but the imaging speed is reduced compared to wide-field microscopy. The penetration depth of confocal microscopy is limited by the signal to background or the signal to noise ratio (6), and only small spheroids can be imaged in toto. A further drawback of confocal microscopy is the high risk of phototoxicity and photobleaching (7). Hence, confocal microscopy is only useful for short time-lapse imaging of living spheroids. Light sheet-based fluorescence microscopy (LSFM) allows the imaging of large three-dimensional specimens over periods of several days $(7,8)$. It provides high acquisition speed and good penetration depth. Photobleaching and phototoxicity are minimized. High-quality imaging with LSFM requires an optimal sample preparation, and standard multi-well plates cannot be used. To achieve full penetration into huge spheroids, multiple views are recorded and subsequently fused (9).

Imaging the sub-micron features of cells requires electron microscopes which have a much higher resolution than light microscopes $(10,11)$. The physical properties of electron microscopes (e.g., high vacuum) demand specific preparation and staining techniques to reveal the ultrastructure of cells and tissues. Sample preparation has to be optimized such that the number of introduced artifacts is minimal (12).

In summary, imaging techniques differ in the amount of detail they provide, which is typically correlated with the amount of effort for sample preparation and imaging (Table 2). Hence, with increasing complexity of the imaging method, the number of samples that can be measured in a given time decreases. Conducting a power analysis based on the expected variability in the measurements provides information on the number of samples required for a statistically sound analysis (13) and hence further restricts the choice of microscope.

\section{Image analysis}

Modern microscopy techniques generate large amounts of data that need to be processed and analyzed. The image analysis has to match the imaging technique and also provide the resulting data in a format that can be readily used as an input for mathematical modeling. Fiji/ImageJ and Icy are two main open-source image analysis platforms that combine a range of standard image analysis tools and advanced plugins in a user-friendly environment $(14,15)$. In addition, more specialized tools with varying degrees of user-friendliness exist. These are described below in the sections on the specific workflows. 


\section{TABLE 2 Imaging and modeling techniques}

\section{Imaging techniques}

\begin{tabular}{|c|c|c|c|c|}
\hline Research question & $\begin{array}{l}\text { Imaging } \\
\text { technique }\end{array}$ & Readout & Experience & $\begin{array}{l}\text { Exemplary } \\
\text { reference }\end{array}$ \\
\hline $\begin{array}{l}\text { Aggregation, spheroid } \\
\text { growth }\end{array}$ & Wide field & 2D projected area & $\begin{array}{l}\text { Multi-sample imaging: } \checkmark \\
\text { Live imaging: } \checkmark \text { (long-term) } \\
\text { No staining necessary: } \checkmark \\
\text { Sample preparation: easy }\end{array}$ & (24) \\
\hline Viability, differentiation & $\begin{array}{l}\text { 2D imaging of } \\
\text { fluorescent or } \\
\text { histological } \\
\text { section }\end{array}$ & $\begin{array}{l}\text { 2D single-cell data } \\
\text { of single slice }\end{array}$ & $\begin{array}{l}\text { Multi-sample imaging: } \checkmark \\
\text { Live imaging: - } \\
\text { No staining necessary: - } \\
\text { Sample preparation: standard }\end{array}$ & $(29,30)$ \\
\hline $\begin{array}{l}\text { Aggregation, } \\
\text { rearrangement, } \\
\text { sorting, adhesion, } \\
\text { viability, and } \\
\text { differentiation }\end{array}$ & $\begin{array}{l}\text { Confocal 3D } \\
\text { imaging }\end{array}$ & 3D single-cell data & $\begin{array}{l}\text { Multi-sample imaging: } \checkmark \\
\text { Live imaging: } \checkmark \text { (short-term) } \\
\text { No staining necessary: - } \\
\text { Sample preparation: advanced }\end{array}$ & (22) \\
\hline $\begin{array}{l}\text { Aggregation, } \\
\text { rearrangement, } \\
\text { sorting, adhesion, } \\
\text { viability, and } \\
\text { differentiation }\end{array}$ & $\begin{array}{l}\text { Light-sheet 3D } \\
\text { imaging }\end{array}$ & 3D single-cell data & $\begin{array}{l}\text { Multi-sample imaging: - } \\
\text { Live imaging: } \checkmark \text { (long-term) } \\
\text { No staining necessary: - } \\
\text { Sample preparation: advanced }\end{array}$ & (17) \\
\hline Adhesion & $\begin{array}{l}\text { Electron } \\
\text { microscopy }\end{array}$ & $\begin{array}{l}\text { Subcellular } \\
\text { structures }\end{array}$ & $\begin{array}{l}\text { Multi-sample imaging: - } \\
\text { Live imaging: - } \\
\text { No staining necessary: - } \\
\text { Sample preparation: advanced }\end{array}$ & (10) \\
\hline \multicolumn{5}{|l|}{ Modeling techniques } \\
\hline Research question & $\begin{array}{l}\text { Modeling } \\
\text { technique }\end{array}$ & Readout & Experience & $\begin{array}{l}\text { Exemplary } \\
\text { reference }\end{array}$ \\
\hline Spheroid growth & Continuous & $\begin{array}{l}\text { Whole spheroid } \\
\text { measures } \\
\text { including shape }\end{array}$ & $\begin{array}{l}+ \text { Fastest } \\
\text { - No single-cell information }\end{array}$ & (56) \\
\hline $\begin{array}{l}\text { Shape and neighbor } \\
\text { changes during } \\
\text { aggregation, cellular } \\
\text { rearrangement, } \\
\text { and sorting; } \\
\text { viability, adhesion, } \\
\text { differentiation }\end{array}$ & $\begin{array}{l}\text { Cellular Potts } \\
\text { model }\end{array}$ & $\begin{array}{l}\text { Typically 2D } \\
\text { single-cell data, } \\
\text { including shape }\end{array}$ & $\begin{array}{l}\text { + Allows for complex shapes } \\
\text { - Computationally slow, cells } \\
\text { restricted to grid }\end{array}$ & (71) \\
\hline $\begin{array}{l}\text { Positional changes } \\
\text { during aggregation, } \\
\text { rearrangement, } \\
\text { and sorting; } \\
\text { viability, adhesion, } \\
\text { differentiation }\end{array}$ & $\begin{array}{l}\text { Centroid } \\
\text { model }\end{array}$ & $\begin{array}{l}\text { 3D single-cell } \\
\text { data excluding } \\
\text { shape }\end{array}$ & $\begin{array}{l}\text { + Flexible, convenient for 3D } \\
\text { - No shape information, } \\
\text { neighborhood has to be } \\
\text { approximated }\end{array}$ & (62) \\
\hline
\end{tabular}




\section{Modeling techniques}

The modeling techniques that have been used in spheroid research so far are distinguished by the details they provide (Table 2). Continuous models regard the spheroid as a whole, neglecting cellular details. The relevant parameters that are typically modeled are shape and size of the whole spheroid over time. Agentbased models, or individual cell-based models as they are sometimes referred to, consider single cells and their respective properties. They are more difficult to implement and require more computational power than continuous models. Agent-based models can be divided into two categories: lattice-free (or off-lattice models) and lattice-based models (16). A common variant of lattice-free models is the centroid model (Figures 2-4). Each cell is assumed to be spherical and defined by its position in space. The cells can have different attributes like radius and protein expression levels. Cell division and cell death can be implemented but the cell shape is neglected. Therefore, the cell neighborhood relations have to be approximated by cell graphs (17).

In lattice-based models, the cells are restricted to a grid. In some variants, a cell is represented by a single grid point on a lattice, and cell movement is implemented as changing from the current grid point to an adjacent grid point. Other lattice-based models depict cells as a cluster of grid points that share the same identifier (Figures 3 and 4). Hence, these models also provide the shape of a cell in addition to its position. A popular representative of this class of models is the Cellular Potts Model.

Several of the modeling approaches have formed the basis for simulation software. Lattice-free software packages like CellSys (18), lattice-based packages such as CompuCell3D (19), and software packages that combine both latticebased and lattice-free methods, for example, Chaste (20) are promising tools for

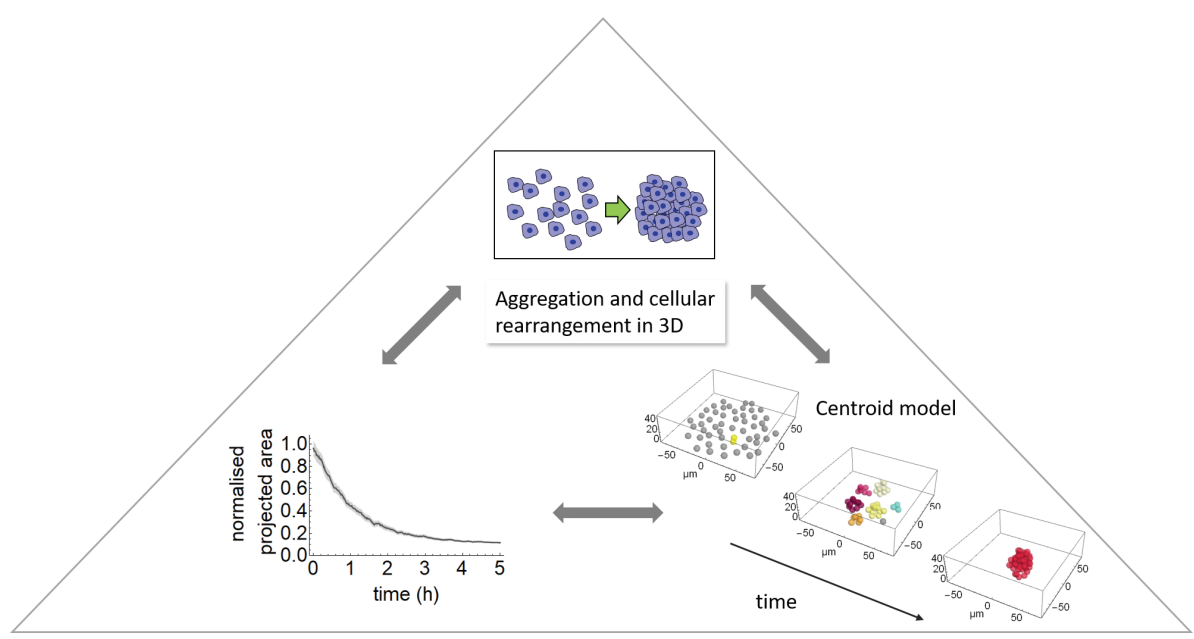

Figure 2 Illustration of the cell biology workflow. Experiments on spheroid formation are combined with quantification of the projected area of the spheroid over time and an agent-based centroid model. The results provide insight into aggregation and cellular rearrangement in three spatial dimensions. 


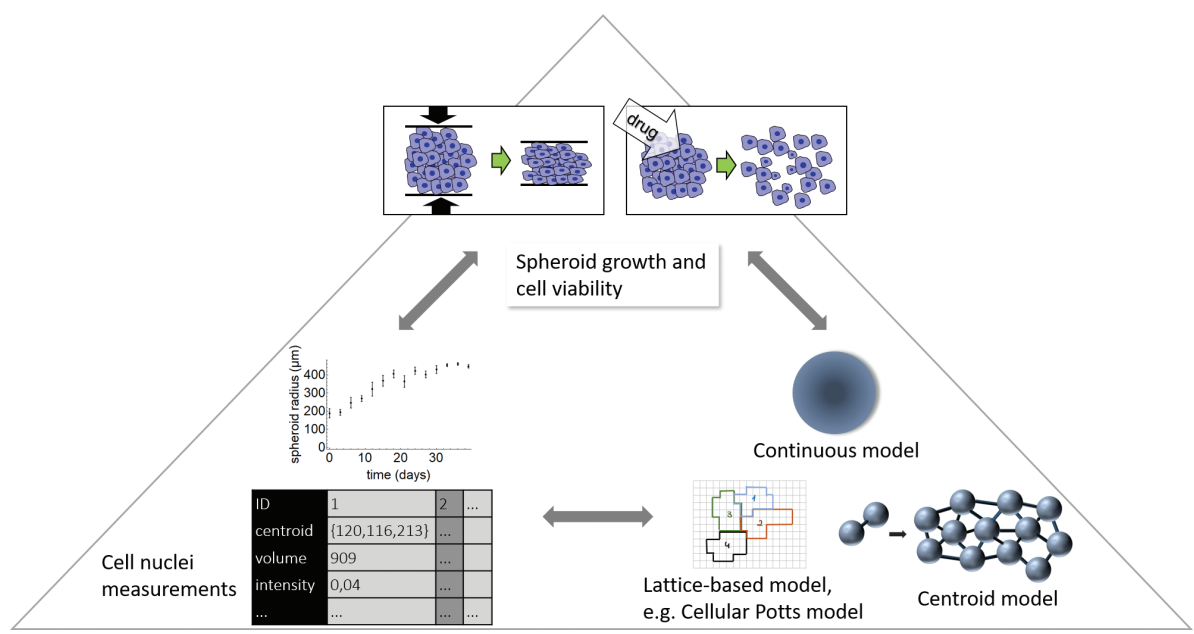

Figure 3 Illustration of the cancer biology workflow. In cancer biology, spheroid growth dynamics, and cell viability are of particular interest. The experiments involve mechanical or chemical perturbations of fully formed spheroids. The quantitative imaging provides global measurements of the spheroid like the radius over time or more detailed single-cell nuclei measurements, depending on the microscopy method employed (see Table 2 for more details). Modeling approaches include continuous models as well as the two types of agent-based models: lattice-based models and centroid models (see Table 2 for more details).

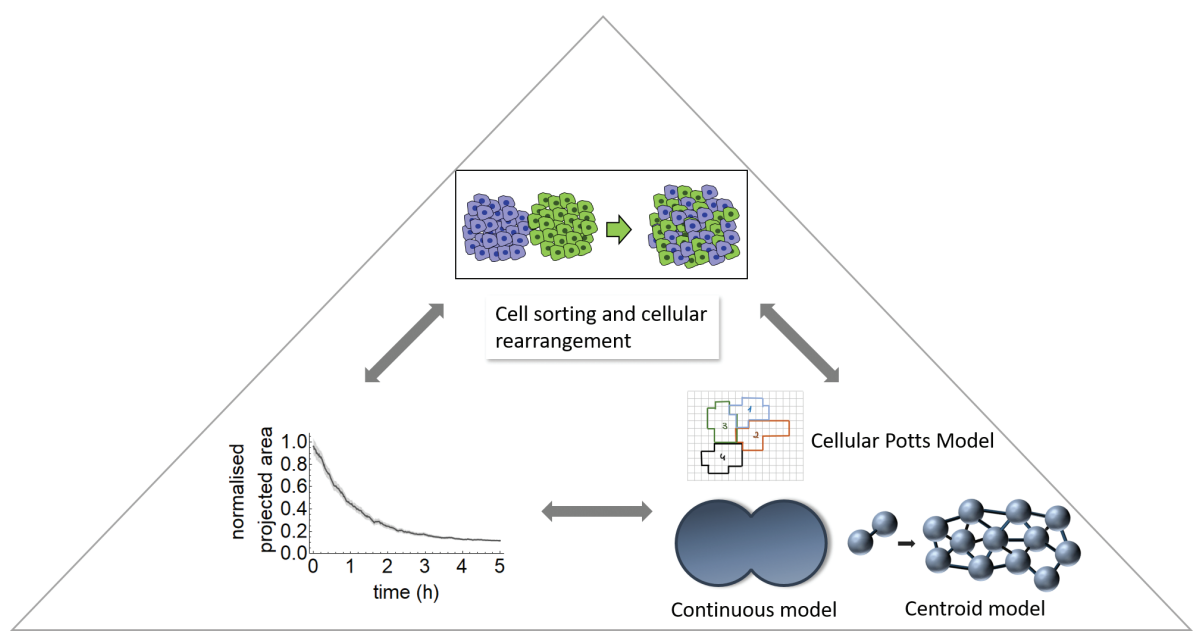

Figure 4 Illustration of the bioprinting workflow. The main spheroid-related question in bioprinting is how cell sorting and cellular rearrangement result in efficient fusion of multiple spheroids. Imaging of spheroid fusion provides the projected area over time. These results have been linked to mathematical models ranging from a continuous approach to agent-based models such as the Cellular Potts model and the centroid model.

implementing individual-based spheroid models. For a given biological question, these packages can form the basis of a model, which then needs to be adapted and extended depending on the required detail. 


\section{FIRST WORKFLOW: CELL BIOLOGY}

Adhesion-based intercellular interactions and cellular rearrangement play an essential role during tissue development and maintenance. Even though both have been extensively studied in two-dimensional cell cultures, there are still a number of open questions regarding the mechanisms active in the three-dimensional context of a tissue. A systems biology approach based on spheroid formation provides the means to study adhesion and cellular rearrangement in a three-dimensional context. Even though these processes certainly vary between cell types, adhesion molecules, such as cadherins and integrins, as well as cytoskeletal components, like actin and microtubules, play a central role. For the experiments, spheroid formation of different cell types $(21,22)$ or the same cell type under different conditions is monitored. Potential variations for the same cell type are the expression of different binding proteins $(23,24)$ or the application of adhesion molecule functional blocking antibodies (21). Studying spheroid formation of cells transfected with wild type or mutant forms of N-cadherin revealed that different cadherin binding sites are responsible for different cell adhesion mechanisms such as the initial binding and the stabilization of an adherence junction. The integrity of spheroids of breast cell lines with different metastatic potential relies on the differential contribution of cadherins, actin, microtubules, and focal adhesion kinase (FAK). In particular, E- or N-cadherin, actin, and microtubules drive the spontaneous aggregation and compaction of the spheroids $(21,22)$. Breast tumor cell lines that require addition of reconstituted basement membrane (Matrigel) for spheroid formation rely on integrin for correct aggregation (21). The activity of FAK correlates with the metastatic potential of the breast cells (22).

\section{Quantitative imaging data}

Visualization of spheroid formation is typically achieved by time-lapse imaging with a wide field or fluorescence microscope. The image acquisition is fast and multi-sample imaging is readily available. This approach provides images of the projected area of the spheroid over time. For the analysis of time-lapse transmission wide field images of spheroid formation, several approaches have been implemented. Saias and colleagues have developed a high-throughput method to monitor and quantify cell aggregation dynamics of colon cancer cells (25). It is based on the segmentation of the projected area of a spheroid. Spheroid edges are identified within the z-projection of the fluorescence image and within a single plane of the transmission image by detecting discontinuities in brightness. The detected spheroid boundary is used to track the spheroid over time. An alternative approach is based on applying a filter with a large kernel to time-lapse spheroid images with fluorescently labeled nuclei and a subsequent binarization (22). This approach does not require a transmission image. If only a transmission image is available, the machine-learning based software ilastik (26) provides a user-friendly environment that is readily applicable (24). Based on manually labeled ground truth data, the algorithm is able to distinguish the spheroid from the background at each time point. Application of ilastik does not require machine-learning expertise. All three segmentation approaches result in time series of the projected area during spheroid formation (Figure 2). 


\section{Spatial mathematical modeling}

For the modeling, spheroid formation has been represented as three-dimensional cell aggregation (Figure 2) (22, 24). A centroid model has been used in which the cells are assumed to be spheres with a given radius and are defined by their position in space. Cells accumulate to form clusters. Cluster formation occurs through cell-cell binding, cell-cluster binding, and cluster-cluster binding. Separation of cells from clusters is also possible. All parameter values are obtained from experimental measures, except for the density difference between cell and medium, which determines the sinking behavior of the cells in the medium as well as the binding and unbinding probabilities. These parameter values are established by fitting the projected area obtained from the model to the experimental data. Relating the resulting binding and unbinding probabilities to the different experimental conditions (cell type, adhesion molecules present, perturbation with antibodies) reveals the effect of the different perturbations on the cellular binding capacities during spheroid formation.

\section{SECOND WORKFLOW: CANCER BIOLOGY}

The most common application of spheroids is in cancer research. Spheroids formed of tumor cells provide a useful model for avascular tumors. Spheroids with diameters above 400-500 $\mu \mathrm{m}$ or more than 30,000 cells establish a concentric cell layering, in which an outer rim of proliferating cells and a layer of quiescent cells surround a necrotic core $(17,27)$. The applications of spheroids have evolved from drug testing to studying fundamental questions underlying cancer biology (28). The governing question is how different kinds of perturbations affect tumor growth.

Of particular interest are treatments with radiation or drugs, or a combination of the two (29). Different oxygen and glucose concentrations in the medium have also provided effects on tumor spheroid growth dynamics (30). Equally important, but not as straightforward, are studies of cellular responses to mechanical perturbations. Since a tumor is subjected to pressure from the surrounding tissue, this consequently confines the tumor, which is thought to affect the regulation of tumor growth (31). Cells are able to sense mechanical forces either directly by deformation or altered organization of intracellular compartments, such as the cytoskeleton (32) or the cell nucleus $(33,34)$, or by mechanoreceptors, which transduce the physical into biochemical or electrical signals (35).

Working with spheroids as a tumor model allows to investigate the influence of forces, which mainly depend on the physical properties of the cells and the extracellular matrix. Several studies have explored the role of mechanical stress on spheroid morphology, cell proliferation, and apoptosis, predominantly in the context of cancer research. Different methods exist to apply pressure on spheroids and to quantify the degree of pressure, time, and the treatment with anti-cancer drugs $(36,37)$.

One option to apply compressive stress on spheroids is an embedment in hydrogel of varying stiffness. These are, for example, composed of protein, agarose, polyacrylamide or polyethylene glycol $(36,38-41)$. Another option is 
incubating a spheroid inside a dialysis bag and applying osmotic pressure with exteriorly added dextran. Long-term compressive stress leads to reduced or inhibited cell proliferation and induction of apoptosis in colon and breast carcinoma cells $(37,42,43)$. Tube-like silicone device also provides a means to confine spheroid growth. Spheroids generated from colorectal cancer cells, which grow inside the device, adapt a rod-like shape. The number of mitotic cells increases, but they exhibit spindle defects and enter mitotic arrest upon confinement (44). Finally, physical confinement on growing spheroids has also been applied by encapsulation in alginate shells. Spheroids generated from mouse colon carcinoma cells show increased cell density and altered cellular organization, and cell proliferation is restricted to the outer rim of the spheroid when compressive stress is applied. An increased number of dead cells occurs in the center of the spheroid (31).

\section{Quantitative imaging data}

Growth curves of fully formed spheroids are usually obtained by wide field timelapse imaging, followed by a segmentation of the projected spheroid area or measuring the spheroid radius over time. These time series measurements are complemented by measurements for each individual cell nucleus including its position, size, and intensity of markers, for example, for cell viability. Images of histological sections (29) or fluorescently stained sections from the spheroid center (30) evaluated by standard nuclei segmentation methods provide this information. To obtain the complete three-dimensional information of the cellular distribution, small spheroids can be imaged in toto with a confocal microscope (22). Larger samples require the combination of optical clearing methods with light sheet microscopy $(17,45)$. For the three-dimensional segmentation of nuclei images, intensity-based methods as well as shape-based methods have been proposed $(17,46-50)$. From these measurements, cell density measurements of the concentric layering can be extracted $(17,51)$.

\section{Spatial mathematical modeling}

The growth dynamics of fully formed spheroids under different conditions have been a major focus of mathematical modeling since the early 70s (52). Over the years, different strategies for spheroid modeling have emerged. Continuum models consider a spheroid as one entity, while agent-based models focus on single cells and their interactions. They are either implemented as lattice-based models, in which the positions of the cells are restricted by a lattice, or as lattice-free approaches (Figure 3).

A lattice-based model that reproduces spheroid growth dynamics was introduced by Radszuweit and colleagues (53). Recently, the model has been extended for a detailed analysis of the behavior of individual cells in a tumor spheroid of non-small cell lung cancer (NSCLC) cell line (30). Based on the images of twodimensional spheroid sections, the distributions of dividing cells, necrotic cells, and the extracellular matrix along the radial direction into the spheroid have been quantified for different glucose levels and spheroids of different ages. An iterative refinement of the model to fit the experimental data has revealed a detailed 
picture of the effect of growth promoters, growth inhibitors, viability promoters, and inhibitors on the growth dynamics of NSCLC spheroids.

Two different centroid models have been developed simultaneously to study the spatio-temporal growth dynamics $(54,55)$. Drasdo and Höhme (54) have shown that nutrient limitation has only a small effect on the expansion velocity. It mainly affects the size of the necrotic core. The relation of this agent-based model to a continuous model has been discussed (56). Schaller and MeyerHermann (55) have fitted the growth curve of their model spheroids to experimental growth curves to determine the ratios of oxygen and glucose uptake rates. Subsequently, the model has been adapted and expanded to study the effect of radiotherapy on tumor spheroids. The cells surviving the treatment exhibit a synchronization of their cell cycle, resulting in time windows of increased radiation sensitivity of the spheroid. Furthermore, reoxygenation occurs with specific timings upon radiotherapy, creating windows of drug treatment opportunities. Respecting the timings of both processes can increase therapy effectiveness (57-59).

The role of mechanical stress in spheroid growth has mostly been studied using continuum models. The models describe volumetric growth behavior of confined, avascular tumor spheroids (60) or the reorganization of cell aggregates following the release of a homogeneous compression (61). Loessner and colleagues have simulated the effect of both mechanical stimulus and different culturing conditions on spheroid growth (36). They have considered different matrix stiffness, culture timings, and drug treatments. Comparison of the modeling results with experimental data has shown a good agreement. The results on cell proliferation in a mechanically perturbed spheroid and spheroid growth influenced by external pressure mentioned above have been obtained by a systems biology approach including agent-based models $(42,43,62)$.

\section{THIRD WORKFLOW: BIOPRINTING}

Bioprinting is emerging as an alternative to scaffold-based tissue engineering. One upcoming method is spheroid printing, which relies on pre-formed spheroids that are used as building blocks for tissue generation. The spheroids are dispensed in regular structures, and the engineered tissue emerges through spheroid fusion and maturation. Arranging the spheroids in a circle and subsequent spheroid fusion produces tissue rings (63) that have been proposed as building blocks for vascular trees $(63,64)$. A similar approach has further led to the formation of tubular structures $(65,66)$. To generate sheet-like structures of engineered adipose tissue, which one day could be used to regenerate the subcutaneous layer of the skin during reconstructive surgery, spheroids formed from adipose cells were placed in a melt electrowritten scaffold (67). After culturing the constructs for 14 days, a continuous tissue layer arose.

The success of these applications, and spheroid printing in general, relies on perfect spheroid fusion. One factor that influences the fusion is the pre-culture time of the single spheroids (68). Increased pre-culture time of spheroids inversely correlates with the fusion rate, suggesting the influence of cell-cell and cell-ECM contact maturation on spheroid-based tissue fusion. Furthermore, the pre-culture 
time of spheroids influences cell-sorting processes that occur during tissue maturation. However, it remains elusive, which further factors control the positioning and collective migration and adhesion of spheroids to form intact and functional tissues.

\section{Quantitative imaging data}

Imaging techniques that have been used in the context of spheroid fusion are electron microscopy (67) as well as two-dimensional bright field and fluorescence images (68). Quantitative analysis of these images with ImageJ resulted in the temporal evolution of the size of the microtissue, which is generated by the fusion of the spheroids.

\section{Spatial mathematical modeling}

Mathematical modeling of tissue fusion started with the work on cell sorting by Glazier and Graner (69) that was based on the differential adhesion hypothesis by Steinberg (70). Implementing a Cellular Potts model, they determined the effect of different adhesion strengths on the sorting of cells. Sego et al. (71) combined such a Cellular Potts model with continuous diffusion modeling. This provides a representation of the behavior of individual cells as well as global characteristics of molecular-level phenomena. The model can reproduce cell sorting, spheroid fusion, and hole closure dynamics. Combining the cell-level dynamics, in particular cell survival with oxygen diffusion through a spheroid, reveals a sensitivity of the spheroid to externally applied oxygen. Applying external oxygen increases cell viability in the spheroid.

Yang et al. (72) employed a continuous model based on phase field theory to model the fusion of cellular aggregates into larger scale structures such as rings, Y-shapes or T-shapes. Spheroids that are located closely together fuse faster than the less densely packed arrangements. Gaps or errors in aggregate deposition can be directly linked to defects in the final biofabricated tissue construct.

To investigate spheroid fusion in three spatial dimensions, Flenner et al. (73) implemented two agent-based centroid models, a kinetic Monte Carlo method and a cellular particle dynamics method. The outline of two fusing aggregates is well represented by both methods. However, they find that the two simulations show clear differences with respect to the speed of cellular rearrangement. For the kinetic Monte Carlo method, fast movement of individual cells, and hence fast rearrangement, results in a complete cell mixing upon tissue fusion. For the cellular particle dynamics model, the fused tissue still exhibits distinct clusters of the different initial cell types. Experimental data to distinguish between the two results are not available so far. Kinetic Monte Carlo simulations have been extended to tube formation as well as $\mathrm{T}$ - and Y-shaped arrangements and the development of vascular tree structures $(74,75)$. The authors considered uniluminal spheroids as well as heterogeneous spheroids formed from a mixture of cells. They show that geometrically this can work; the question is how the cells survive in such structures. Also, they found that timesaving due to tight packing of the initial configuration of the spheroids is negligible compared to the time the system takes for fusion to steady state. 


\section{OUTLOOK: EXPERIMENTS INSPIRED BY THE MATHEMATICAL MODELS}

The three exemplary research areas for spheroids have shown that these cell aggregates are a widely applicable in vitro system. Furthermore, major drawbacks of the current state of systems biology approaches for spheroids have become apparent. For all three research areas, agent-based models exist. In the centroid models, the properties of each cell including its position, marker expression, and its connection to neighboring cells are known at each time point. However, in most cases, the quantitative imaging data for testing these detailed predictions from the models are missing. A step further would be to also consider the threedimensional shape of a cell in a spheroid. Three-dimensional Cellular Potts model exist to tackle this question, but again the experimental data are missing.

Confocal or light-sheet imaging in combination with innovative sample preparation methods $(45,76)$ and staining protocols $(77)$ can provide the necessary images. Evaluating these images with single-cell-based segmentation and a subsequent analysis with neighborhood graphs (17) can provide the necessary data to refine the complex models. This will provide detailed insight into the spatial interactions of cells in spheroids.

So far, all experimental approaches focus on the spheroid as a closed unit. However, the modeling of spheroid fusion by Fenner et al. raised the question of the cellular dynamics within the spheroid. Do cells in spheroids move and how fast do they rearrange? Three-dimensional live imaging of individual cells in spheroids can provide insight, and the application of the existing cell tracking approaches (78) can yield the quantitative data to validate the mathematical models.

Most applications of spheroids still focus on spheroid growth or intercellular adhesion mainly in the context of cancer. However, these are not the only processes that are different between two-dimensional and three-dimensional cell cultures. Various proteins including keratin, vimentin, heat shock proteins, chaperons, and proteins involved in glucose metabolism have been shown to be differently expressed in two-dimensional cell culture versus three-dimensional cell culture (79). Therefore, the next steps are to address other cellular processes like cell polarization and cell differentiation and to address further diseases apart from cancer.

\section{CONCLUSION}

Systems biology approaches are slowly evolving towards spheroid research. In many studies, the different parts (Figure 1) are still well separated. Further efforts have to be made that integrate experiments, quantitative imaging, and mathematical modeling into a whole. This requires close interactions between experts from different disciplines including biology, medicine, physics, mathematics, and computer science. The most integral part of these interactions is a good communication, a common language or the interest to learn and understand the other's language. The collaboration has to start when developing the scientific question. 
This ensures that the experimental and theoretical methods that are applied match well and are adequate to address the question of interest.

For some research questions, it might be necessary to adapt the threedimensional cell culture system. Apart from spheroids, cysts are useful to study cell polarization in epithelia. Embryonic stem cell aggregates like ICM organoids (80), blastoids (81) or gastruloids (82) allow the investigation of cell differentiation during early mammalian embryogenesis. Three-dimensional multicellular structures grown from more specialized stem cells are typically called organoids. They consist of organ-specific cell types and are employed to mimic a variety of human tissues including brain, lung, liver, intestine, kidney, and pancreas. Applications range from studying fundamental questions of organ development and diseases to toxicity testing and personalized medicine (83). The main concepts introduced in this review are readily extendable to these other types of three-dimensional cell culture systems. In all cases, a major effort has to be put on combining information from different sources with the spatial distribution of the cells within the multicellular system.

Acknowledgements: The author thanks Isabell Smyrek, Biena Mathew, Katharina Hötte, Ernst H.K. Stelzer and Silvia Muñoz-Descalzo for their fruitful discussions and valuable inputs, and Ezgi Eylül Bankoglu and Simon Schardt for critical reading of the manuscript.

Conflict of interest: The author declares no potential conflicts of interest with respect to research, authorship, and/or publication of this chapter.

Copyright and permission statement: To the best of my knowledge, the materials included in this chapter do not violate copyright laws. All original sources have been appropriately acknowledged and/or referenced. Where relevant, appropriate permissions have been obtained from the original copyright holder(s).

\section{REFERENCES}

1. Duval K, Grover H, Han L-H, Mou Y, Pegoraro AF, Fredberg J, et al. Modeling physiological events in 2D vs. 3D cell culture. Physiology. 2017 Jul;32(4):266-77. http://dx.doi.org/10.1152/ physiol.00036.2016

2. Sutherland R. Cell and environment interactions in tumor microregions: the multicell spheroid model. Science. 1988 Apr 8;240(4849):177-84. http://dx.doi.org/10.1126/science.2451290

3. Figge MT, Murphy RF. Image-based systems biology. Cytometry A. 2015;87(6):459-61. http://dx.doi. org/10.1002/cyto.a.22663

4. Hirschhaeuser F, Menne H, Dittfeld C, West J, Mueller-Klieser W, Kunz-Schughart LA. Multicellular tumor spheroids: An underestimated tool is catching up again. J Biotechnol. $2010 \mathrm{Jul} \mathrm{1;148(1):3-15.}$ http://dx.doi.org/10.1016/j.jbiotec.2010.01.012

5. Sirenko O, Mitlo T, Hesley J, Luke S, Owens W, Cromwell EF. High-content assays for characterizing the viability and morphology of 3D cancer spheroid cultures. ASSAY Drug Dev Technol. 2015 Sep;13(7):402-14. http://dx.doi.org/10.1089/adt.2015.655

6. Smithpeter CL, Dunn AK, Welch AJ, Richards-Kortum R. Penetration depth limits of in vivo confocal reflectance imaging. Appl Opt. 1998;37(13):2749-54. http://dx.doi.org/10.1364/AO.37.002749

7. Stelzer EHK. Light-sheet fluorescence microscopy for quantitative biology. Nat Methods. 2015 Jan;12(1):23-6. http://dx.doi.org/10.1038/nmeth.3219 
8. Pampaloni F, Chang B-J, Stelzer EHK. Light sheet-based fluorescence microscopy (LSFM) for the quantitative imaging of cells and tissues. Cell Tissue Res. 2015 Apr;360(1):129-41. http://dx.doi. org/10.1007/s00441-015-2144-5

9. Swoger J, Verveer P, Greger K, Huisken J, Stelzer EHK. Multi-view image fusion improves resolution in three-dimensional microscopy. Optic Express. 2007 Jun 25;15(13):8029-42. http://dx.doi. org/10.1364/OE.15.008029

10. Almarshad HA, Madhavan M, Hoshino K. Focused ion beam-based milling, imaging and analysis of 3D tumor spheroids. In: 2018 40th Annual International Conference of the IEEE Engineering in Medicine and Biology Society (EMBC). 2018 Jul;2018:4480-4483. http://dx.doi.org/10.1109/ EMBC.2018.8513165

11. Zhang J, Whitehead J, Liu Y, Yang Q, Leach JK, Liu G. Direct observation of tunneling nanotubes within human mesenchymal stem cell spheroids. J Phys Chem B. 2018 Nov 1;122(43):9920-6. http:// dx.doi.org/10.1021/acs.jpcb.8b07305

12. Böttcher B. Transmission electron microscopy: Preparation of specimens. In: John Wiley \& Sons, Ltd, editor. eLS. Chichester, UK: John Wiley \& Sons, Ltd, 2012; p. a0002998.pub2.

13. Quinn GP, Keough MJ. Experimental design and data analysis for biologists. Cambridge: Cambridge University Press, 2002; p. 537.

14. Schindelin J, Arganda-Carreras I, Frise E, Kaynig V, Longair M, Pietzsch T, et al. Fiji: An opensource platform for biological-image analysis. Nat Methods. 2012 Jul;9(7):676-82. http://dx.doi. org/10.1038/nmeth.2019

15. de Chaumont F, Dallongeville S, Chenouard N, Hervé N, Pop S, Provoost T, et al. Icy: an open bioimage informatics platform for extended reproducible research. Nat Methods. 2012 Jul;9(7):690-6. http://dx.doi.org/10.1038/nmeth.2075

16. Glen CM, Kemp ML, Voit EO. Agent-based modeling of morphogenetic systems: Advantages and challenges. PLoS Comput Biol. 2019 Mar 28;15(3):e1006577. http://dx.doi.org/10.1371/journal. pcbi. 1006577

17. Schmitz A, Fischer SC, Mattheyer C, Pampaloni F, Stelzer EHK. Multiscale image analysis reveals structural heterogeneity of the cell microenvironment in homotypic spheroids. Sci Rep. 2017 Dec;7(1):43693. http://dx.doi.org/10.1038/srep43693

18. Hoehme S, Drasdo D. A cell-based simulation software for multi-cellular systems. Bioinformatics. 2010 Oct 15;26(20):2641-2. http://dx.doi.org/10.1093/bioinformatics/btq437

19. Swat MH, Thomas GL, Belmonte JM, Shirinifard A, Hmeljak D, Glazier JA. Multi-scale modeling of tissues using CompuCell3D. In: Methods in cell biology. Elsevier; 2012;110:325-366 https://doi. org/10.1016/B978-0-12-388403-9.00013-8

20. Mirams GR, Arthurs CJ, Bernabeu MO, Bordas R, Cooper J, Corrias A, et al. Chaste: An open source C++ library for computational physiology and biology. PLoS Comput Biol. 2013 Mar 14;9(3):el002970. http://dx.doi.org/10.1371/journal.pcbi.1002970

21. Ivascu A, Kubbies M. Diversity of cell-mediated adhesions in breast cancer spheroids. Int J Oncol. 2007 Dec 1;31:1403-13. http://dx.doi.org/10.3892/ijo.31.6.1403

22. Smyrek I, Mathew B, Fischer SC, Lissek SM, Becker S, Stelzer EHK. E-cadherin, actin, microtubules and FAK dominate different spheroid formation phases and important elements of tissue integrity. Biol Open. 2018 Dec 21;8:10.1242/bio.037051. http://dx.doi.org/10.1242/bio.037051

23. Bunse S, Garg S, Junek S, Vogel D, Ansari N, Stelzer EHK, et al. Role of N-cadherin cis and trans interfaces in the dynamics of adherens junctions in living cells. Hotchin NA, editor. PLoS ONE. 2013 Dec 2; 8(12):e81517. http://dx.doi.org/10.1371/journal.pone.0081517

24. Garg S, Fischer SC, Schuman EM, Stelzer EHK. Lateral assembly of N-cadherin drives tissue integrity by stabilizing adherens junctions. J R Soc Interface. 2015 Mar 6;12(104):20141055. http://dx.doi. org/10.1098/rsif.2014.1055

25. Saias L, Gomes A, Cazales M, Ducommun B, Lobjois V. Cell-cell adhesion and cytoskeleton tension oppose each other in regulating tumor cell aggregation. Cancer Res. 2015 Jun 15;75(12):2426-33. http://dx.doi.org/10.1158/0008-5472.CAN-14-3534

26. Sommer C, Straehle C, Kothe U, Hamprecht FA. Ilastik: Interactive learning and segmentation toolkit. In: 2011 IEEE International Symposium on Biomedical Imaging: From Nano to Macro. Chicago, IL: IEEE, March 30-April 2, 2011. p. 230-3. 
27. Kunz-Schughart LA, Freyer JP, Hofstaedter F, Ebner R. The use of 3-D cultures for high-throughput screening: The multicellular spheroid model. J Biomol Screen. 2004 Jun;9(4):273-85. http://dx.doi. org/10.1177/1087057104265040

28. Ravi M, Paramesh V, Kaviya SR, Anuradha E, Solomon FDP. 3D cell culture systems: Advantages and applications: 3D cell culture systems. J Cell Physiol. 2015 Jan;230(1):16-26. http://dx.doi. org/10.1002/jcp. 24683

29. Mao X, McManaway S, Jaiswal JK, Patel PB, Wilson WR, Hicks KO, et al. An agent-based model for drug-radiation interactions in the tumour microenvironment: Hypoxia-activated prodrug SN30000 in multicellular tumour spheroids. PLOS Comput Biol. 2018 Oct 24;14(10):e1006469. http://dx.doi. org/10.1371/journal.pcbi.1006469

30. Jagiella N, Müller B, Müller M, Vignon-Clementel IE, Drasdo D. Inferring growth control mechanisms in growing multi-cellular spheroids of NSCLC cells from spatial-temporal image data. Byrne H, editor. PLoS Comput Biol. 2016 Feb 11;12(2):e1004412. http://dx.doi.org/10.1371/journal.pcbi.1004412

31. Alessandri K, Sarangi BR, Gurchenkov VV, Sinha B, Kiessling TR, Fetler L, et al. Cellular capsules as a tool for multicellular spheroid production and for investigating the mechanics of tumor progression in vitro. Proc Natl Acad Sci. 2013 Sep 10;110(37):14843-8. http://dx.doi.org/10.1073/ pnas. 1309482110

32. Luo T, Mohan K, Iglesias PA, Robinson DN. Molecular mechanisms of cellular mechanosensing. Nat Mater. 2013 Nov;12(11):1064-71. http://dx.doi.org/10.1038/nmat3772

33. Philip JT, Dahl KN. Nuclear mechanotransduction: Response of the lamina to extracellular stress with implications in aging. J Biomech. 2008 Nov;41(15):3164-70. http://dx.doi.org/10.1016/j. jbiomech.2008.08.024

34. Guilak F, Tedrow JR, Burgkart R. Viscoelastic properties of the cell nucleus. Biochem Biophys Res Commun. 2000;269(3):781-6. http://dx.doi.org/10.1006/bbrc.2000.2360

35. DuFort CC, Paszek MJ, Weaver VM. Balancing forces: Architectural control of mechanotransduction. Nat Rev Mol Cell Biol. 2011 May;12(5):308-19. http://dx.doi.org/10.1038/nrm3112

36. Loessner D, Flegg JA, Byrne HM, Clements JA, Hutmacher DW. Growth of confined cancer spheroids: A combined experimental and mathematical modelling approach. Integr Biol. 2013 Feb 25;5(3): 597-605. http://dx.doi.org/10.1039/c3ib20252f

37. Delarue M, Montel F, Vignjevic D, Prost J, Joanny J-F, Cappello G. Compressive stress inhibits proliferation in tumor spheroids through a volume limitation. Biophys J. 2014 Oct;107(8):1821-8. http:// dx.doi.org/10.1016/j.bpj.2014.08.031

38. Sieminski AL, Was AS, Kim G, Gong H, Kamm RD. The stiffness of three-dimensional ionic selfassembling peptide gels affects the extent of capillary-like network formation. Cell Biochem Biophys. 2007 Oct 1;49(2):73-83. http://dx.doi.org/10.1007/s12013-007-0046-1

39. Helmlinger G, Netti PA, Lichtenbeld HC, Melder RJ, Jain RK. Solid stress inhibits the growth of multicellular tumor spheroids. Nat Biotechnol. 1997 Aug;15(8):778. http://dx.doi.org/10.1038/ nbt0897-778

40. Cheng G, Tse J, Jain RK, Munn LL. Micro-environmental mechanical stress controls tumor spheroid size and morphology by suppressing proliferation and inducing apoptosis in cancer cells. Blagosklonny MV, editor. PLoS One. 2009 Feb 27;4(2):e4632. http://dx.doi.org/10.1371/journal.pone.0004632

41. Paszek MJ, Zahir N, Johnson KR, Lakins JN, Rozenberg GI, Gefen A, et al. Tensional homeostasis and the malignant phenotype. Cancer Cell. 2005 Sep 1;8(3):241-54. http://dx.doi.org/10.1016/j. ccr.2005.08.010

42. Montel F, Delarue M, Elgeti J, Malaquin L, Basan M, Risler T, et al. Stress clamp experiments on multicellular tumor spheroids. Phys Rev Lett. 2011 Oct 24;107(18):188102. http://dx.doi.org/10.1103/ PhysRevLett.107.188102

43. Montel F, Delarue M, Elgeti J, Vignjevic D, Cappello G, Prost J. Isotropic stress reduces cell proliferation in tumor spheroids. New J Phys. 2012 May 9;14(5):055008. http://dx.doi.org/10.1088/ $1367-2630 / 14 / 5 / 055008$

44. Desmaison A, Frongia C, Grenier K, Ducommun B, Lobjois V. Mechanical stress impairs mitosis progression in multi-cellular tumor spheroids. Engler AJ, editor. PLoS One. 2013 Dec 3;8(12):e80447. http://dx.doi.org/10.1371/journal.pone.0080447 
45. Hoette K, Koch M, Hof L, Tuppi M, Moreth T, Stelzer EHK, et al. Ultra-thin fluorocarbon foils optimize multiscale imaging of three-dimensional native and optically cleared specimens. bioRxiv. 2019 Feb 12. http://dx.doi.org/10.1101/533844

46. Mathew B, Schmitz A, Muñoz-Descalzo S, Ansari N, Pampaloni F, Stelzer EHK, et al. Robust and automated three-dimensional segmentation of densely packed cell nuclei in different biological specimens with Lines-of-Sight decomposition. BMC Bioinformatics. 2015 Dec;16(1):187. http:// dx.doi.org/10.1186/s12859-015-0617-x

47. Friebel A, Neitsch J, Johann T, Hammad S, Hengstler JG, Drasdo D, et al. TiQuant: Software for tissue analysis, quantification and surface reconstruction. Bioinformatics. 2015 Oct 1;31(19):3234-6. http://dx.doi.org/10.1093/bioinformatics/btv346

48. Morales-Navarrete H, Segovia-Miranda F, Klukowski P, Meyer K, Nonaka H, Marsico G, et al. A versatile pipeline for the multi-scale digital reconstruction and quantitative analysis of 3D tissue architecture. eLife. 2015 Dec 27;4:e11214. http://dx.doi.org/10.7554/eLife.11214

49. McQuin C, Goodman A, Chernyshev V, Kamentsky L, Cimini BA, Karhohs KW, et al. CellProfiler 3.0: Next-generation image processing for biology. Misteli T, editor. PLoS Biol. 2018 Jul 3;16(7):e2005970. http://dx.doi.org/10.1371/journal.pbio.2005970

50. Lou X, Kang M, Xenopoulos P, Muñoz-Descalzo S, Hadjantonakis A-K. A rapid and efficient 2D/3D nuclear segmentation method for analysis of early mouse embryo and stem cell image data. Stem Cell Rep. 2014 Mar 11;2(3):382-97. http://dx.doi.org/10.1016/j.stemcr.2014.01.010

51. Dini S, Binder BJ, Fischer SC, Mattheyer C, Schmitz A, Stelzer EHK, et al. Identifying the necrotic zone boundary in tumour spheroids with pair-correlation functions. J R Soc Interface. 2016 Oct 1; 13(123):20160649. http://dx.doi.org/10.1098/rsif.2016.0649

52. Byrne HM. Dissecting cancer through mathematics: from the cell to the animal model. Nat Rev Cancer. 2010 Mar;10(3):221-30. http://dx.doi.org/10.1038/nrc2808

53. Radszuweit M, Block M, Hengstler JG, Schöll E, Drasdo D. Comparing the growth kinetics of cell populations in two and three dimensions. Phys Rev E. 2009 May 12;79(5):051907. http://dx.doi. org/10.1103/PhysRevE.79.051907

54. Drasdo D, Höhme S. A single-cell-based model of tumor growthin vitro: monolayers and spheroids. Phys Biol. 2005 Jul;2(3):133-147. http://dx.doi.org/10.1088/1478-3975/2/3/001

55. Schaller G, Meyer-Hermann M. Multicellular tumor spheroid in an off-lattice Voronoi-Delaunay cell model. Phys Rev E. 2005 May 27;71(5):051910. http://dx.doi.org/10.1103/PhysRevE.71.051910

56. Byrne H, Drasdo D. Individual-based and continuum models of growing cell populations: A comparison. J Math Biol. 2008 Oct 8;58(4):657. http://dx.doi.org/10.1007/s00285-008-0212-0

57. Kempf H, Bleicher M, Meyer-Hermann M. Spatio-temporal cell dynamics in tumour spheroid irradiation. Eur Phys J D. 2010 Oct;60(1):177-93. http://dx.doi.org/10.1140/epjd/e2010-00178-4

58. Kempf H, Hatzikirou H, Bleicher M, Meyer-Hermann M. In silico analysis of cell cycle synchronisation effects in radiotherapy of tumour spheroids. Alber MS, editor. PLoS Comput Biol. 2013 Nov 14; 9(11):e1003295. http://dx.doi.org/10.1371/journal.pcbi.1003295

59. Kempf H, Bleicher M, Meyer-Hermann M. Spatio-temporal dynamics of hypoxia during radiotherapy. Rocha S, editor. PLoS One. 2015 Aug 14;10(8):e0133357. http://dx.doi.org/10.1371/journal. pone. 0133357

60. Ciarletta P, Ambrosi D, Maugin GA, Preziosi L. Mechano-transduction in tumour growth modelling. Eur Phys J E. 2013 Mar;36(3):23. http://dx.doi.org/10.1140/epje/i2013-13023-2

61. Giverso C, Preziosi L. Modelling the compression and reorganization of cell aggregates. Math Med Biol. 2012 Jun 1;29(2):181-204. http://dx.doi.org/10.1093/imammb/dqr008

62. Liedekerke PV, Neitsch J, Johann T, Alessandri K, Nassoy P, Drasdo D. Quantitative agent-based modeling reveals mechanical stress response of growing tumor spheroids is predictable over various growth conditions and cell lines. PLoS Comput Biol. 2019 Mar 8;15(3):el006273. http://dx.doi. org/10.1371/journal.pcbi.1006273

63. Mironov V, Visconti RP, Kasyanov V, Forgacs G, Drake CJ, Markwald RR. Organ printing: Tissue spheroids as building blocks. Biomaterials. 2009 Apr;30(12):2164-74. http://dx.doi.org/10.1016/j. biomaterials.2008.12.084 
64. Patra S, Young V. A review of 3D printing techniques and the future in biofabrication of bioprinted tissue. Cell Biochem Biophys. 2016 Jun;74(2):93-8. http://dx.doi.org/10.1007/sl2013-016-0730-0

65. Yurie H, Ikeguchi R, Aoyama T, Kaizawa Y, Tajino J, Ito A, et al. The efficacy of a scaffold-free Bio $3 \mathrm{D}$ conduit developed from human fibroblasts on peripheral nerve regeneration in a rat sciatic nerve model. Nógrádi A, editor. PLoS One. 2017 Feb 13;12(2):e0171448. http://dx.doi.org/10.1371/journal.pone.0171448

66. Taniguchi D, Matsumoto K, Tsuchiya T, Machino R, Takeoka Y, Elgalad A, et al. Scaffold-free trachea regeneration by tissue engineering with bio-3D printing. Interact Cardiovasc Thorac Surg. 2018 May 1; 26(5):745-52. http://dx.doi.org/10.1093/icvts/ivx444

67. McMaster R, Hoefner C, Hrynevich A, Blum C, Wiesner M, Wittmann K, et al. Tailored melt electrowritten scaffolds for the generation of sheet-like tissue constructs from multicellular spheroids. Adv Healthc Mater. 2019 Apr 1;8(7):1801326. http://dx.doi.org/10.1002/adhm.201801326

68. Rago AP, Dean DM, Morgan JR. Controlling cell position in complex heterotypic 3D microtissues by tissue fusion. Biotechnol Bioeng. 2009;102(4):1231-41. http://dx.doi.org/10.1002/bit.22162

69. Glazier JA, Graner F. Simulation of the differential adhesion driven rearrangement of biological cells. Phys Rev E. 1993 Mar 1;47(3):2128-54. http://dx.doi.org/10.1103/PhysRevE.47.2128

70. Steinberg MS. Reconstruction of tissues by dissociated cells. Science. 1963 Aug 2;141(3579):401-8. http://dx.doi.org/10.1126/science.141.3579.401

71. Sego TJ, Kasacheuski U, Hauersperger D, Tovar A, Moldovan NI. A heuristic computational model of basic cellular processes and oxygenation during spheroid-dependent biofabrication. Biofabrication. 2017 Jun;9(2):024104. http://dx.doi.org/10.1088/1758-5090/aa6ed4

72. Yang X, Mironov V, Wang Q. Modeling fusion of cellular aggregates in biofabrication using phase field theories. J Theor Biol. 2012 Jun;303:110-8. http://dx.doi.org/10.1016/j.jtbi.2012.03.003

73. Flenner E, Janosi L, Barz B, Neagu A, Forgacs G, Kosztin I. Kinetic Monte Carlo and cellular particle dynamics simulations of multicellular systems. Phys Rev E. 2012 Mar 8;85(3):031907. http://dx.doi. org/10.1103/PhysRevE.85.031907

74. Sun Y, Wang Q. Modeling and simulations of multicellular aggregate self-assembly in biofabrication using kinetic Monte Carlo methods. Soft Matter. 2013 Jul 31;9(7):2172-86. http://dx.doi. org/10.1039/c2sm27090k

75. Sun Y, Yang X, Wang Q. In-silicoanalysis on biofabricating vascular networks using kinetic Monte Carlo simulations. Biofabrication. 2014 Jan;6(1):015008. http://dx.doi.org/10.1088/1758-5082/6/1/015008

76. Jeandupeux E, Lobjois V, Ducommun B. 3D print customized sample holders for live light sheet microscopy. Biochem Biophys Res Commun. 2015 Aug;463(4):1141-3. http://dx.doi.org/10.1016/j. bbrc.2015.06.072

77. Smyrek I, Stelzer EHK. Quantitative three-dimensional evaluation of immunofluorescence staining for large whole mount spheroids with light sheet microscopy. Biomed Opt Express. 2017 Feb 1; 8(2):484-99. http://dx.doi.org/10.1364/BOE.8.000484

78. Tinevez J-Y, Perry N, Schindelin J, Hoopes GM, Reynolds GD, Laplantine E, et al. TrackMate: An open and extensible platform for single-particle tracking. Methods. 2017 Feb 15;115:80-90. http://dx.doi. org/10.1016/j.ymeth.2016.09.016

79. Pampaloni F, Stelzer EHK, Leicht S, Marcello M. Madin-Darby canine kidney cells are increased in aerobic glycolysis when cultured on flat and stiff collagen-coated surfaces rather than in physiological 3-D cultures. Proteomics. 2010 Aug 17;10(19):3394-413. http://dx.doi.org/10.1002/pmic.201000236

80. Mathew B, Muñoz-Descalzo S, Corujo-Simon E, Schröter C, Stelzer EHK, Fischer SC. Mouse ICM organoids reveal three-dimensional cell fate clustering. Biophys J. 2019 Jan 8;116:127-41. http:// dx.doi.org/10.1016/j.bpj.2018.11.011

81. Rivron NC, Frias-Aldeguer J, Vrij EJ, Boisset J-C, Korving J, Vivié J, et al. Blastocyst-like structures generated solely from stem cells. Nature. 2018 May;557(7703):106. http://dx.doi.org/10.1038/ s41586-018-0051-0

82. Beccari L, Moris N, Girgin M, Turner DA, Baillie-Johnson P, Cossy A-C, et al. Multi-axial self-organization properties of mouse embryonic stem cells into gastruloids. Nature. 2018 Oct;562(7726):272. http://dx.doi.org/10.1038/s41586-018-0578-0

83. Clevers H. Modeling development and disease with organoids. Cell. 2016 Jun;165(7):1586-97. http://dx.doi.org/10.1016/j.cell.2016.05.082 